\title{
Special Issue Call for Proposals
}

\section{The State, Global Markets, and the Clean Energy Transition}

This special issue examines the interaction of state and global markets in the development of clean energy technologies such as solar, wind, and electric vehicles. First, papers will explore how global markets shape the domestic politics of clean energy policy. For instance, how do global supply chains, global competition, and industry structure affect the domestic politics of developing clean energy industries and of transitioning toward a sustainable energy system? How do global market dynamics shape the non-market strategies of firms toward clean energy and technology policy? Second, papers will investigate how differences in domestic industrial and regulatory policies on clean energy shape global markets. For example, how do policy leaders versus followers impact global clean energy markets? How do policies that stimulate technology supply and policies that promote technology demand combine in the global diffusion of clean technology?

Taken together, this special issue will connect recent debates in comparative and international political economy with the increasingly empirically relevant global transition toward clean energy. It has a dedicated focus on domestic-global interactions and on sector-specific market dynamics.

Papers should be no longer than 8,500 words (excluding the bibliography) and should be accompanied by a letter to the editors explaining the paper's relevance to the special issue. Submit your paper using the Business and Politics online submission site by June 15, 2017. Directions for manuscript preparation can also be found there. Please direct all inquiries to Jonas Meckling (meckling@berkeley.edu) and Llewelyn Hughes (1lewelyn.hughes@anu.edu.au).Publication is slated for Fall 2018.

Directions for manuscript preparation can be found here:

https://www.cambridge.org/core/journals/business-and-politics/information/instructions-contributors.

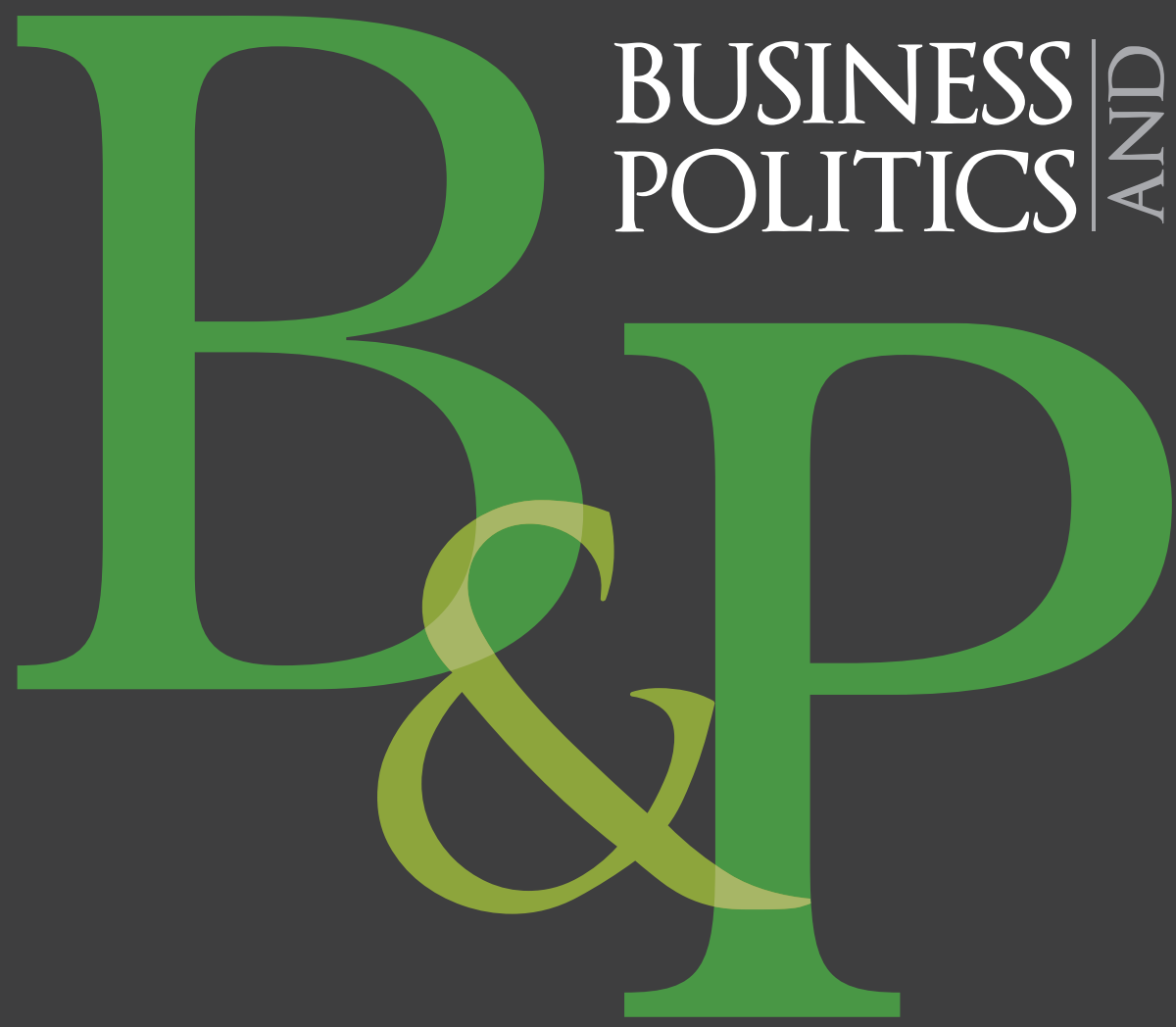

